\title{
Aged care clinical mentoring model of change in nursing homes in China: study protocol for a cluster randomized controlled trial
}

Hui Feng ${ }^{1 *}$, Hui Li ${ }^{1}$, Lily Dongxia Xiao ${ }^{2^{*}}$ (D), Shahid Ullah ${ }^{3}$, Pan Mao ${ }^{4}$, Yunxia Yang ${ }^{1}$, Hengyu Hu${ }^{1}$ and Yinan Zhao ${ }^{1}$

\begin{abstract}
Background: Residents living in nursing homes usually have complex healthcare needs and require a comprehensive care approach to identifying and meeting their care needs. Suboptimal quality of care is reported in nursing homes and is associated with the poor health and well-being of the residents, the burden on acute care hospitals and the high costs of healthcare for the government.

The aim of this study is to test the hypothesis that an Aged Care Clinical Mentoring Model will create and sustain evidence-based quality improvement in priority areas and will be cost-effective in nursing homes in Hunan Province, China.
\end{abstract}

Methods: A cluster randomized controlled trial will be applied to the study. Fourteen nursing homes will be randomly allocated to either the intervention group $(n=7)$ or the control group $(n=7)$. Forty staff will be recruited from each nursing home and the estimated sample size will be 280 staff in each group. The intervention includes a structured, evidence-based quality improvement education program for staff to facilitate knowledge translation in evidence-based quality improvement targeting urinary incontinence, pressure injury and falls prevention. The primary outcomes are nursing homes' capacity to create and sustain quality improvement, staff perceptions of person-centered care, selfreported quality of care by residents and selected quality indicators at 12 months follow-up adjusted for baseline value. Secondary outcomes are residents' quality of life, residents' unplanned admissions to acute care hospitals, quality of care reported by staff, staff job satisfaction and staff intention to leave adjusted for baseline value. A mixed linear regression model will be adopted to compare the significant differences between groups over a 12-month period.

Discussion: Although the Aged Care Clinical Mentoring Model has been tested as an effective model to bring positive changes in nursing homes in a high-income country, factors affecting the adaptation of the model in nursing homes in low- and middle-income countries are unknown. The carefully planned intervention protocol enables the project team to consider enablers and barriers when adapting the Model. Therefore, strategies and resources will be in place to manage challenges while demonstrating best practice in this study.

Trial registration: Prospectively registered via Chinese Clinical Trial Registry (ChiCTR), ChiCTR-IOC-17013109, Registered on 25 October 2017.

Keywords: Cluster randomized controlled trial, Mentoring, Nursing home, Quality of care, Quality improvement

\footnotetext{
* Correspondence: feng.hui@csu.edu.cn; lily.xiao@flinders.edu.au

'Xiangya school of nursing, Central South University, Changsha, Hunan

province, China

${ }^{2}$ College of Nursing and Health Sciences, Flinders University, GPO Box 2100,

Adelaide, SA 5001, Australia

Full list of author information is available at the end of the article
}

(c) The Author(s). 2018 Open Access This article is distributed under the terms of the Creative Commons Attribution 4.0 International License (http://creativecommons.org/licenses/by/4.0/), which permits unrestricted use, distribution, and reproduction in any medium, provided you give appropriate credit to the original author(s) and the source, provide a link to the Creative Commons license, and indicate if changes were made. The Creative Commons Public Domain Dedication waiver (http://creativecommons.org/publicdomain/zero/1.0/) applies to the data made available in this article, unless otherwise stated. 


\section{Background}

The Chinese population is aging dramatically due to improved life-expectancy and a decrease in fertility rate [1]. In 2016, the number of people aged over 60 years reached 230 million [2]. It was also estimated that more than 100 million people aged 60 years or over had chronic diseases [3]. The number of older people living with disabilities reached 37 million and those living with dementia reached 9.19 million [3]. The demand for nursing home care for older people with high-dependence care needs has reached an unprecedented high in China [1]. By 2016, the number of nursing homes was 140 thousand with 7.3 million beds, and the average annual growth rate of nursing home beds was $8.6 \%$ nation-wide [4]. The majority of residents in nursing homes have dementia or cognitive impairment [5]. The rapid growth of nursing homes has raised great concern in the public about the quality of care for nursing home residents in China [6]. There are few evidence-based intervention studies to improve quality of care in nursing homes. This study will address the gap in research by adapting and evaluating an Aged Care Clinical Mentoring Model that has been tested as an effective model of change in evidence-based quality improvement in nursing homes in Australia [7].

Similar to many low- and middle-income countries, China has experienced significant social and economic transitions in the past four decades, characterized by improved employment rates for women and increased internal migration for employment or career development opportunities. This surge in employment for women has weakened the traditional family-based care for older people, [1] the demand for nursing home care for older people has increased dramatically due to the lack of family caregivers $[1,8]$. However, nursing homes are currently underdeveloped to provide residents with high-quality care, evidenced by reports on unmet care needs, suboptimal care and high hospitalization rates [6].

Lack of workforce development to implement evidencebased quality of care for residents is one of the key factors amongst many that contribute to undesirable care outcomes in nursing homes [9]. Registered nurses are a minority in the workforce in nursing homes, and have limited educational preparation in leading nursing home care [10]. A large proportion of staff members in nursing homes are untrained personal care assistants (PCAs) who are mainly migrant workers from rural areas and have low levels of education with little to no training in nursing home care [10]. In addition, a low staff to resident ratio in nursing homes is widely reported and is attributed to unmet care needs for residents [10].

Quality of care is defined as "the degree to which health services for individuals and populations increase the likelihood of desired health outcomes and are consistent with current professional knowledge" [11, 12]. This definition strongly suggests that quality improvement needs to be based on current research evidence. Staff education about evidence-based practice and knowledge translation activities are two crucial components in evidence-based quality improvement [7, 13]. However, nursing homes are usually perceived as resource-poor settings for implementing evidence-based quality improvement [14]. Building nursing homes' capacity to create and sustain quality improvement is a priority in the aged care system to ensure that quality of care is achieved [15].

The most frequently reported indicators of poor quality care in a Chinese nursing home context are falls, fall-related injuries, pressure ulcers and urinary incontinence among residents. Residents living with dementia are associated with a high risk of these poor quality care outcomes [16]. The estimated prevalence rate of urinary incontinence is around $65.8 \%$, the fall rate is around $14.7-34 \%$ and the pressure ulcer rate is around $7.1-25 \%$ in nursing homes in China [17-19]. Prevention of these adverse events has been identified as a priority quality improvement as they have negative consequences for residents and for healthcare costs [18].

Clinical Mentor as a model of change in evidence-based quality improvements has been widely reported and recognized as a successful model globally [20, 21]. An Aged Care Clinical Mentor (ACCM) is defined as "a leader who facilitates improved quality of care for older people using best practice by providing and encouraging professional development in colleagues through communication, education and peer support" $[9,21,22]$. In the ACCM model in Australia, Registered Nurses (RNs) were prepared and supported to lead evidence-based quality improvement activities and were appointed as a clinical mentor for care staff (mentees). The ACCM model was initiated by the Australian Government and was tested in four aged care facilities and four community aged care settings across two states in Australia $[9,22]$. The results revealed that the ACCM model was an effective workforce model to improve aged care organizations' capacity to create and sustain quality improvement [9]. The aim of this study is to create and sustain quality improvement in nursing homes by implementing the ACCM model in Hunan Province, China.

\section{Methods \\ Study design}

The ACCM model will be tested using a single-blind cluster randomized controlled trial (RCT) design. The study will be undertaken in Hunan Province, the seventh largest populated province in China, and home to 12.01 million people aged 60 or over where one-sixth of them were living with disabilities in 2015 [23]. Fourteen nursing homes in Hunan Province will be randomly selected and divided into two groups: the intervention group and 
the control group. Cluster RCT will be applied to the study to reduce influence from the interplay of subjects from the same nursing home. Because of the nature of the intervention, it is not possible to mask the study assignment from the research interventionists (the project team who will deliver the intervention), though staff at participating sites will be unaware of group assignment. The outcomes assessment will be performed by independent investigators who will be blinded to the group assignment. The standard protocol items named "Recommendations for Interventional Trials (SPIRIT)" that provides an overview of schedule of enrolment, interventions and assessments is presented in Table 1. The SPIRIT checklist is shown in Additional file 1.

\section{Hypotheses}

Primary hypothesis: Nursing homes that implement the ACCM model will report enhanced capacity to create and sustain evidence-based quality $\left(\mathrm{H}_{1}\right)$, improved staff perceptions of person-centered care $\left(\mathrm{H}_{2}\right)$, and higher levels of residents' or their families' perception of quality of care $\left(\mathrm{H}_{3}\right)$ compared to the control group.

Secondary hypothesis: Nursing homes that implement the ACCM model will report improved quality of life for residents $\left(\mathrm{H}_{4}\right)$, reduced unplanned admissions to acute care hospitals $\left(\mathrm{H}_{5}\right)$, higher staff perception of quality of care $\left(\mathrm{H}_{6}\right)$, increased job satisfaction for staff $\left(\mathrm{H}_{7}\right)$, and decreased staff intention to leave $\left(\mathrm{H}_{8}\right)$.

\section{Inclusion and exclusion criteria}

Nursing homes will be included in the study if: (i) they have 150 beds or more; (ii) they have RNs in each unit; (iii) they are willing to participate in the study voluntarily. Nursing homes will be excluded from the study if they are participating in other training and research activities.

\section{Participants and sample size}

Participants will be staff who provide direct care for residents. The sample size is based on one of the primary outcomes: staff perceptions of person-centered care measured by the Approaches to Dementia Questionnaire' (ADQ). In an earlier cluster RCT to improve care quality and safety through a 12-month clinical leadership program in aged care [24], the researchers found no differences in care staff attitudes toward dementia and dementia care assessed by ADQ between the intervention and control sites at 12 months post-intervention. Therefore, in our study, we have set a clinically meaningful change of $1.0 \mathrm{ADQ}$ scores and $85 \%$ power to detect a difference of 1.2 standard deviation between groups at the $5 \%$ level of significance.

Table 1 schedule of enrolment, interventions and assessments

\begin{tabular}{|c|c|c|c|c|c|}
\hline \multirow[b]{3}{*}{ TIME POINT } & \multicolumn{5}{|c|}{$\underline{\text { STUDY PERIOD }}$} \\
\hline & \multirow{2}{*}{$\begin{array}{l}\text { Enrollment } \\
-\mathrm{T}_{1}\end{array}$} & \multirow{2}{*}{$\begin{array}{l}\text { Allocation } \\
<\mathrm{T}_{0}\end{array}$} & \multicolumn{3}{|c|}{ Intervention Period } \\
\hline & & & $\mathrm{T}_{0}$ & $\mathrm{~T}_{6}$ & $\mathrm{~T}_{12}$ \\
\hline \multicolumn{6}{|l|}{ ENROLLMENT: } \\
\hline Eligibility screen & $\mathrm{X}$ & & & & \\
\hline Informed consent & $\mathrm{X}$ & & & & \\
\hline Randomization and Allocation & & $\mathrm{X}$ & & & \\
\hline \multicolumn{6}{|l|}{ INTERVENTIONS: } \\
\hline \multicolumn{6}{|l|}{ ACCM Model } \\
\hline \multicolumn{6}{|l|}{ Control } \\
\hline \multicolumn{6}{|l|}{ ASSESSMENTS: } \\
\hline Nursing homes' capacity to create and sustain quality & & & $\mathrm{X}$ & $\mathrm{X}$ & $\mathrm{X}$ \\
\hline Perceptions of quality of care & & & $\mathrm{X}$ & $\mathrm{X}$ & $\mathrm{X}$ \\
\hline Person-centered Care Assessment & & & $\mathrm{X}$ & $\mathrm{X}$ & $\mathrm{X}$ \\
\hline Staff job satisfaction & & & $\mathrm{X}$ & $\mathrm{X}$ & $\mathrm{X}$ \\
\hline Staff intentions to leave & & & $\mathrm{X}$ & $\mathrm{X}$ & $\mathrm{X}$ \\
\hline Residents' quality of life & & & $\mathrm{X}$ & $\mathrm{X}$ & $\mathrm{X}$ \\
\hline Quality indicators & & & $\mathrm{X}$ & $\mathrm{X}$ & $\mathrm{X}$ \\
\hline Economic evaluation & & & $\mathrm{X}$ & & $\mathrm{X}$ \\
\hline
\end{tabular}

Note: $\mathrm{ACCM}=$ Aged Care Clinical Mentor 
Since randomization will be conducted by the nursing homes (clusters), the sample size was adjusted to take into account the design effect. We have considered a large intra-class correlation coefficient of 0.26 (average estimate from a nursing home staff training intervention carried out in England and Wales [25]) and an average cluster size of 40 nursing staff. Assuming an alpha error of 0.05 and a beta error of $20 \%$, the required cluster number was 7 for each group (251 nursing staff per group). Allowing for an attrition rate of $10-12 \%$, we would require around 280 staff in each arm of the project.

\section{Randomization}

Based on research experience, only nursing homes with 150 beds or more have RNs on each unit to manage care services and to supervise PCAs. Moreover, there are two types of nursing.

homes: state-owned nursing homes and not-for-profit privately-owned nursing homes (the majority) and the former has a greater wealth of resources. The size of nursing homes and sources of funding are major characteristics that influence quality of care [26]. To minimize difference between the two groups, participating nursing homes will be grouped into four categories according to ownership and size, and modified stratification will be applied to the group assignment to improve the equivalence of the intervention group and the control group. Computer generated random numbers will be used for group assignment and this will be performed by an independent statistician (see Fig. 1).

\section{Description of the ACCM model intervention}

This study has adapted the key characteristics of the Australian ACCM Model of Change described as the 'Six Steps to Better Practice' (see Fig. 2). The organizational structure of the ACCM Model is outlined in Fig. 3. The Steering Committee will be specifically established for this trial and will comprise the Principle Investigator, Co-Principle Investigators, Hunan Government representatives, representatives from the main project participants and representatives from the seven intervened nursing homes. Each nursing home will appoint a RN as a Clinical Mentor and each unit will appoint a RN or licensed nurse as a Site Champion.

\section{Description of the ACCM model intervention}

The intervention components, as described in the following section, will continue for 12 months. An evidence-based knowledge translation education program will be developed to enable the implementation of the ACCM model, and includes five modules: (i) Introduction to ACCM model; (ii) Leadership and clinical coaching in ACCM model; (iii) Urinary incontinence prevention; (iv) Pressure injury prevention and (v) falls prevention (see Table 2). The education program is based on the aim of the trial and the priorities in quality improvement identified by stakeholders in an industry consultation and a comprehensive literature search. The train-the-trainer method will be applied to implement the education program in which the Clinical Mentors will attend a 3-day intensive workshop (modules 1-5) and the Site Champions will attend a 2-day workshop (modules 2-5). The Clinical Mentor will work in

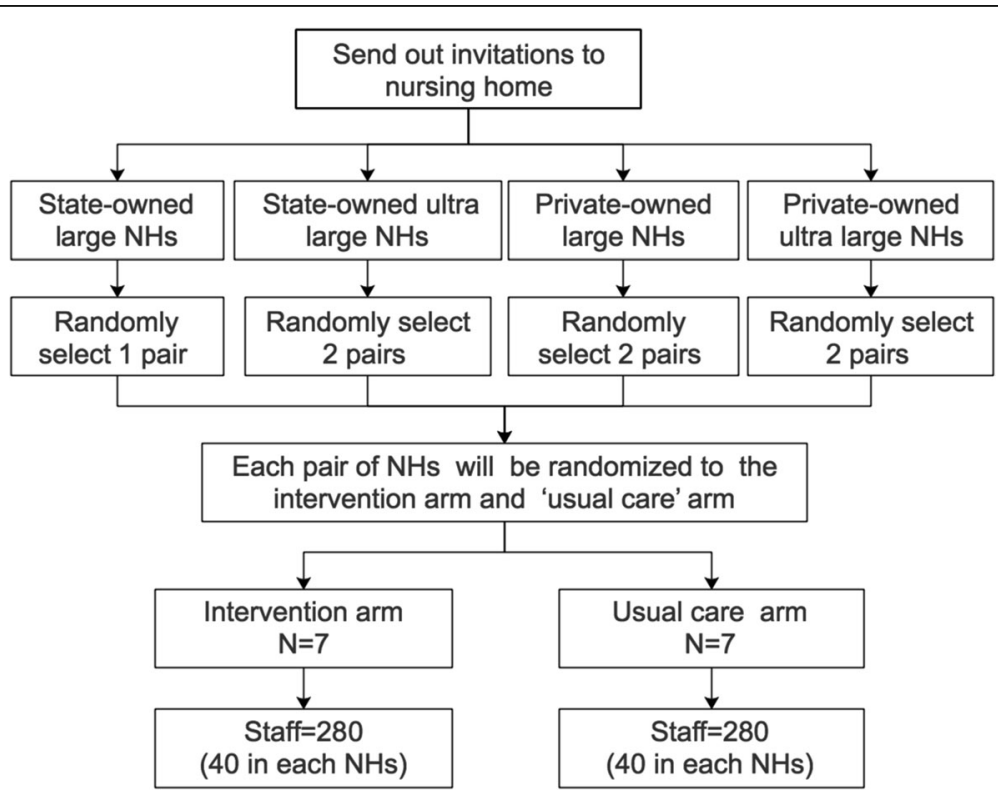

Fig. 1 Randomization 


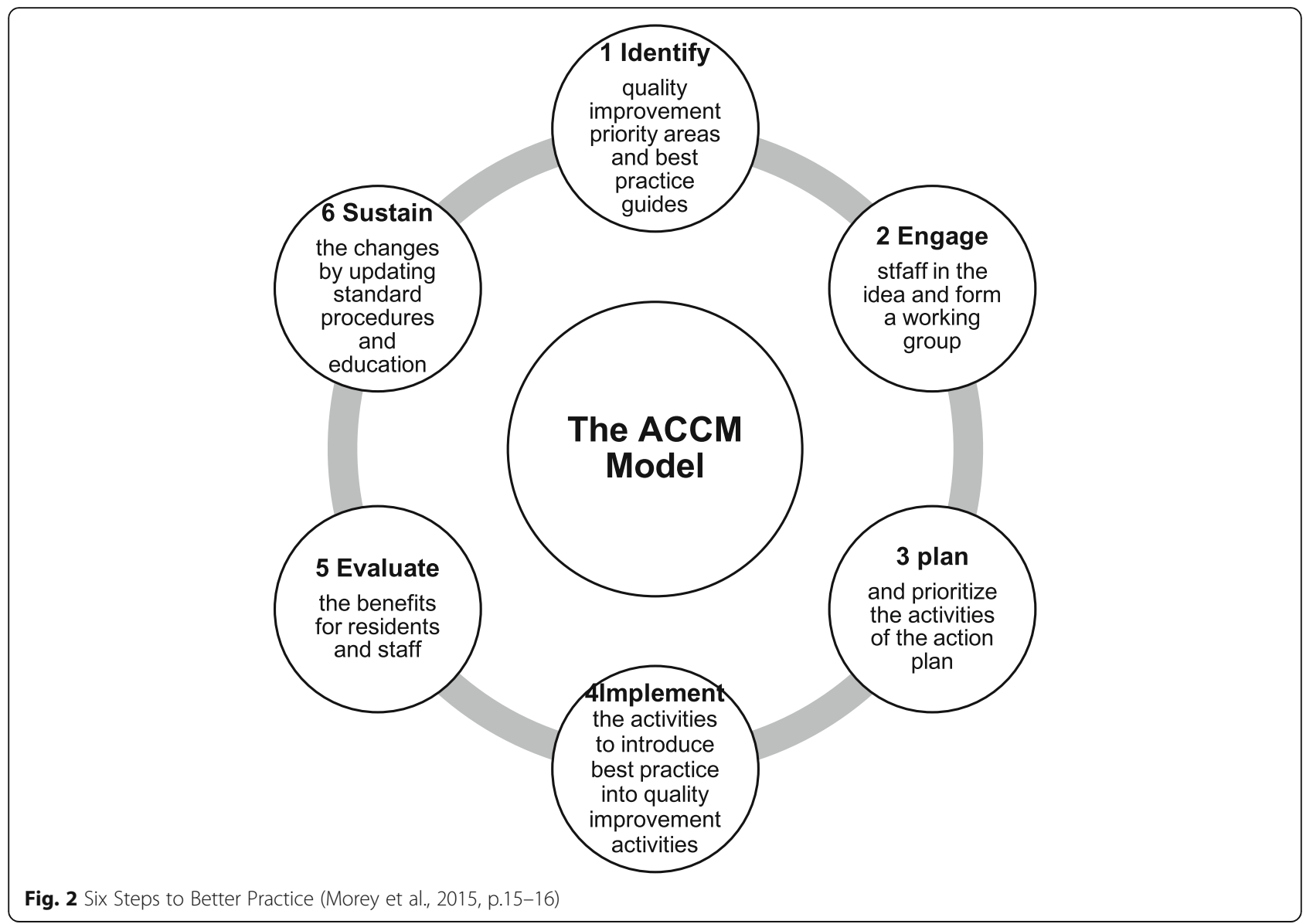

collaboration with the Site Champions to implement the education program through education and training activities for staff. In each learning module, the project team will provide the Clinical Mentors and Site Champions with facilitator's manuals and provide staff with a workbook to enhance interactive learning.

The Clinical Mentors will develop an action plan every three months and discuss the action plan in the regular Steering Committee meetings in order to gain feedback from the Committee to revise or amend the plan. The
Clinical Mentor will also receive regular written feedback based on the analysis of outcome measures on baseline data, and at 6 and 12 months post-intervention to foster quality improvement. An Academic Coach, who is an academic member of the University and is specialized in geriatric nursing, will be appointed to support Clinical Mentors to implement the action plan, monitor the process, and update standards, procedures, and in-service education based on the outcomes of the project. The Clinical Mentors and Site Champions will

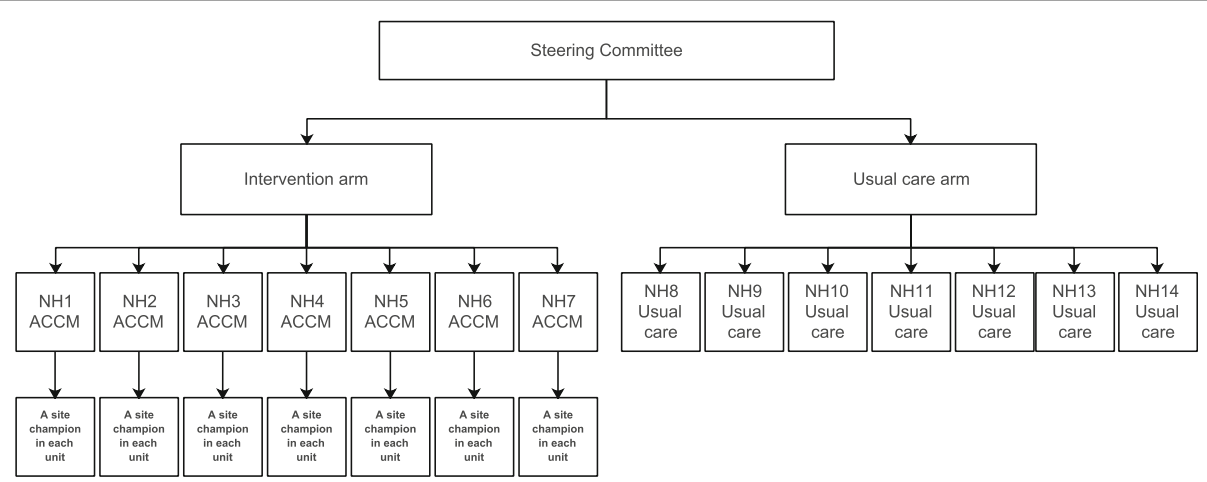

Fig. 3 Organizational Structure of the ACCM Model 
Table 2 Structured and Evidence-Based Quality Improvement Education Program

\begin{tabular}{ll}
\hline Modules & Participants \\
\hline $\begin{array}{l}\text { Module 1. The strategies and procedures } \\
\text { for the Aged Care Clinical Mentor to } \\
\text { Create and Sustain Quality Improvement }\end{array}$ & ACCMs \\
$\begin{array}{l}\text { Module 2. Effective leadership and } \\
\text { clinical coaching for staff }\end{array}$ & ACCMs \& Site Champions \\
$\begin{array}{l}\text { Module 3. Evidence-based urinary } \\
\text { incontinence management for } \\
\text { residents }\end{array}$ & ACCMs \& Site Champions \\
$\begin{array}{l}\text { Module 4. Evidence-based pressure } \\
\text { injury prevention for residents }\end{array}$ & ACCMs \& Site Champions \\
$\begin{array}{l}\text { Module 5. Evidence-based falls } \\
\text { prevention }\end{array}$ & ACCMs \& Site Champions \\
\hline
\end{tabular}

Note: ACCMs $=$ Aged Care Clinical Mentors

be given paid time of eight hours per week to deliver education modules and mentor staff to translate knowledge at the point of care.

\section{Description of control group}

Nursing homes in the control group will receive routine training and information about the current care standards for residents that are applicable all nursing homes in Hunan Province. If they have further questions about the quality of care for the project team, they will be referred to relevant resources provided by the Hunan Provincial Civil Affairs Department that, again, are available to all nursing homes.

\section{Recruitment}

Recruitment of nursing homes and care staff will be based on the selection criteria. A letter of invitation will be sent to all eligible nursing home managers to gain their informed consent to participate in the trial. Managers will administer confidentiality agreements regarding group assignment with the project team. However, the ACCM model will be introduced to all participating nursing homes after the trial.

\section{Outcome measures and data collection Primary outcomes}

Primary outcomes include: (i) Nursing homes' capacity to create and sustain quality improvement; (ii) Staff perceptions of Person-centered Care; (iii) Self-reported quality of care by residents; and (iv) quality indicators that include falls, fall-related injuries, pressure ulcers and urinary incontinence at 12 months follow-up adjusted for baseline value.

\section{Secondary outcomes}

Secondary outcomes are the following outcomes adjusted for baseline value: (i) Residents' quality of life; (ii) Residents' unplanned admissions to acute care hospitals due to adverse events, as described in the primary outcomes; (iii) Self-reported quality of care by staff; (iv) Staff job satisfaction; (v) Staff intention to leave.

\section{Instruments}

The instruments and their relationship to outcomes and hypotheses are presented in Table 3 [12, 27-33].

\section{Economic evaluation}

Medical costs for each resident will be documented and collected in relation to treatment for fall-related injuries, new pressure ulcers, new urinary tract infections, and visits and readmissions to acute care hospitals. Cost-effectiveness will be expressed through a cost saving ratio and/or the outcomes per cost of intervention.

\section{Data collection}

The data will be collected before the intervention, and at 6 and 12 months after the commencement of intervention, for both intervention and control groups. A project manager will be appointed to coordinate the data collection process. Independent investigators who are blind to study assignment will distribute, collect and assist residents and staff to complete the survey. The Clinical Mentors in the intervention arm, and a liaison person in each control nursing home, will be tasked to work together with the project manager to complete the incident record form on falls, fall-related injuries, pressure ulcers and urinary tract infections on a weekly basis. The quality indicators will be carefully tracked by the following methods: (i) weekly follow-up and surveillance of the adverse events that will be recorded and submitted by the site managers; (ii) checking of residents' progress notes and handover reports by research assistants to verify the incidents.

Each staff member and resident will be assigned a code number to protect their identity. This will also allow the researcher to re-identify them if needed. In order to be able to link all three surveys together without revealing staff identities, the project team will implement an identification method in which care staff members will be asked to write their maternal grandparents' first names next to a unique site character on the front page of each survey.

\section{Statistical methods}

Data from the trial will be analyzed using STATA software version 14.0 (Stata Corp, College Station, Texas, USA). All data will be checked for accuracy and a missing data analysis will be undertaken. The trial will adhere to the 'CONSORT statement: extension to cluster randomized trials' [34]. The data will be analyzed on an intention-to-treat basis, based on patient assignment.

A mixed linear regression model will be adopted to compare the significant differences between groups over a 12-month period. The mixed linear regression model 
Table 3 Description of instruments used in outcome measures

\begin{tabular}{|c|c|c|}
\hline Outcomes & Instruments description & Hypotheses \\
\hline $\begin{array}{l}\text { Nursing homes' capacity to create } \\
\text { and sustain quality improvement }\end{array}$ & $\begin{array}{l}\text { Shortell's Organization and Management Survey had been adapted } \\
\text { to nursing home to evaluate nursing homes' capacity to create and } \\
\text { sustain quality improvement by Scott [27]. The scale has } 35 \text { items, } \\
\text { consists of } 5 \text { subscales related to communication and leadership. } \\
\text { Cronbach's a of the Chinese version is } 0.87 \text { [27]. }\end{array}$ & $\begin{array}{l}\mathrm{H}_{1} \text { - nursing homes' capacity to create } \\
\text { and sustain evidence-based quality }\end{array}$ \\
\hline $\begin{array}{l}\text { Perceptions of quality } \\
\text { of care }\end{array}$ & $\begin{array}{l}\text { A single item on a 4-point Likert scale which is dichotomized as } \\
\text { very low or rather low opposed to rather high or very high [12]. }\end{array}$ & $\mathrm{H}_{6} \& \mathrm{H}_{3}$ - perception of quality of care \\
\hline $\begin{array}{l}\text { Person-centered Care } \\
\text { Assessment Tool }\end{array}$ & $\begin{array}{l}\text { Person-centered Care Assessment Tool consists of three subscales: } \\
\text { the extent of personalizing care, amount of organizational support, } \\
\text { degree of environmental accessibility, Cronbach's a of the Chinese } \\
\text { version is } 0.68[28,29] \text {. }\end{array}$ & $\begin{array}{l}\mathrm{H}_{2} \text { - staff's perceptions of Person- } \\
\text { centered Care }\end{array}$ \\
\hline Staff job satisfaction & $\begin{array}{l}\text { Minnesota Satisfaction Questionnaire in short form has } 20 \text { items was } \\
\text { used to examine satisfaction with professional life, Cronbach's a of } \\
\text { the Chinese version is } 0.95 \text { [30]. }\end{array}$ & $\mathrm{H}_{7^{-}}$job satisfaction \\
\hline Staff intentions to leave & $\begin{array}{l}\text { Turnover Intention Scale has } 6 \text { items and Items are scored using 4-point } \\
\text { Likert. The Chinese version has been tested and used to assess the } \\
\text { turnover intention of care staff. Cronbach's a of the Chinese version } \\
\text { is } 0.92 \text { [31]. }\end{array}$ & $\mathrm{H}_{8}$ - staff intention to leave \\
\hline \multirow[t]{2}{*}{ Residents' quality of life } & $\begin{array}{l}\text { The12-item Short-Form Health Survey has } 8 \text { domains include Physical } \\
\text { Functioning, Role-Physical, Bodily Pain, General Health, Vitality, Social } \\
\text { Functioning, Role-Emotional, and Mental Health. Cronbach's a of the } \\
\text { Chinese version is } 0.91 \text { [32]. }\end{array}$ & \multirow[t]{2}{*}{$\mathrm{H}_{4}$ - residents' quality of life } \\
\hline & $\begin{array}{l}\text { Quality of Life in Late-Stage of Dementia has } 3 \text { factors and } 11 \text { items, with } \\
\text { the factors being depressive mood, behavioral symptoms of discomfort, } \\
\text { and positive behavioral signs of social interaction. Cronbach's a of the } \\
\text { Chinese version is } 0.74 \text { [33]. }\end{array}$ & \\
\hline
\end{tabular}

will be adjusted by baseline value and potential confounding variables, for example, the sites and staff education levels [35]. Two-sided tests will be performed for all analyses and the level of significance will be set at $P<0.05$. Where appropriate, $95 \%$ confidence interval will also be reported along with the $P$ values.

\section{Economic analysis}

The cost-effectiveness of the ACCM model intervention will be evaluated by comparison of the intervention cost to the expected key outcomes. The following model will be used:

$$
\text { Cost Effectiveness }=\left(\frac{\text { Cost }_{\text {New }}-\text { Cost }_{\text {Old }}}{\text { Effest }_{\text {New }}-\text { Effest }_{\text {Old }}}\right)
$$

\section{Trial status}

We commenced a pilot study in November 2017 to test the implementation of learning modules in two sites outside of the selected sites in the main study. The pilot study will be completed by September 2018. The main study will take 20 months, and is expected to be completed by August 2020.

\section{Discussion}

Previous studies demonstrated that use of the mentor and champion model in the workplace promoted evidence-based practice in acute care hospitals [36-38]. However, there are barriers to implementing this model in nursing homes. First, mentees, who are mainly unlicensed personal care assistants, require the Clinical Mentor to assess their learning needs and initiate learning activities to meet their needs at the point of care. The present project has considered this contextual factor and has allocated eight hours per week for the Clinical Mentor and Site Champions to work with personal care assistants in the education program. Second, nursing homes are viewed as resource-poor settings for conducting education and training for staff [39]. Developing educational resources for staff engaged in the evidence-based quality improvements is imperative. In the present study, the learning modules developed to support the trial will address the education resource issue. The train-the-trainer model and coaching for Site Champions are crucial intervention components that were previously reported in a successful evidence-based quality improvement study [40]. The present study has adapted these components, but emphasizes leadership for Clinical Mentors and Site Champions in the intervention context.

Organizational support through investing time and budget in staff development is viewed as a prerequisite for successful quality improvement [40, 41]. In the present study, the in-kind contributions made by participating nursing homes to support the time the Clinical Mentor and Site Champions spend on the intervention is evidence 
of organizational support. Policy development to mandate staff education and training is a way to enable and sustain organizational commitment to evidence-based quality improvement in nursing homes in low- and middle-income countries. China is progressing in improving its aged care system which is evidenced by government administered regulations and requisite standards; organizational and governance structures; required staff to resident ratio; and required education and training qualification for staff [42]. All nursing homes are required to meet the standards for nursing homes for accreditation by the National Health and Family Planning Commission of the People's Republic of China [43]. Nursing homes that have agreed to participate in the study view the ACCM model as an opportunity to establish an organizational structure for sustainable quality improvement and staff development. In the consultation with these participating nursing homes, the management group particularly valued the audit activities embedded in the study, as the audit data provided them with timely and relevant information about quality improvement. The management group also sees this study as an opportunity to empower personal care staff to participate in decision-making processes in quality improvement in which their perspectives about change will be heard.

One of the challenges identified in the previous study was the resistance to the ACCM program from management and staff because staffing levels were low, and mentoring activities and changes in practice were viewed as additional workload for staff [10]. We have considered this challenge and will streamline mentoring activities in existing staff training and supervision activities in the workplace with minimal interference to routine care activities based on consultation with management and staff. Clinical Mentors and Site Champions will implement learning activities at opportunistic moments and at the point of care [39]. The packet workbook for staff allows them to access learning resources to work with the Clinical Mentor in learning opportunities including bedside coaching in residents' rooms when appropriate. This was tested in a previous mentor and champion model where mentoring activities provided staff with timely support in problem solving, which was successful in reducing their stress levels and improving their job satisfaction and staff retention [24].

The learning modules for staff are mainly based on short case studies that have been collected from the nursing home environment and are relevant to staff members' daily care activities. These authentic case studies have been adapted to simulate problems and provide solutions in quality improvement. These case studies also enable staff to reflect on their situations and empower them to consider different approaches to problem solving. Case studies also encourage staff to build teamwork, collaboration and adjust their actions in the team in order to generate collective action for better outcomes for residents.

This study comes at an opportune time to introduce the ACCM Model of Change to implement evidence-based quality improvements in nursing homes in China where suboptimal care services are reported and concerns have been raised by the public [6]. The Central Government and the Provincial Government are taking action to address quality of care evidenced by policies, standards and regulations for nursing homes [42]. Findings from this study will inform evidence-based policy to govern quality and safety in nursing homes. Findings will also support policy and resource development to ensure adequate staffing and RNs' leadership in evidence-based practice and quality improvement in nursing homes.

\section{Additional file}

Additional file 1: SPIRIT 2013 Checklist. (DOC 138 kb)

\section{Abbreviations}

ACCM: Aged Care Clinical Mentor; ADQ: Approaches to Dementia

Questionnaire; PCAs: Personal Care Assistants; RCT: Randomized controlled trial; RNs: Registered Nurses

\section{Acknowledgements}

We would like to acknowledge the support of the Department of Civil Affairs of Hunan Province. We would also like to acknowledge James A Wiley from University of California, San Francisco, and You S Liu from The Second Xiangya Hospital of Central South University for their assistance with the research proposal.

\section{Funding}

This project was funded by China Medical Board. Grant number: 17-268.

\section{Availability of data and materials}

Datasets generated from this study will be available from the corresponding author on reasonable request. The researchers have full access to the datasets. The researchers will publish results of the study when the data collection and analysis are completed.

\section{Authors' contributions}

HF and LDX have conceived the study. HF, LDX, HL, PM, and YY drafted and revised this manuscript including all figures and Tables. SU contributed to the sample size calculation, designed the statistical analysis, and critically reviewed the manuscript. $\mathrm{HF}, \mathrm{HL}, \mathrm{YY}, \mathrm{HH}$ and $\mathrm{YZ}$ conducted industry consultation for the development of the trial. All authors critically reviewed and approved the final manuscript.

\section{Ethics approval and consent to participate}

Ethical Approval was gained from the Nursing and Behavioral Medicine Institutional Review Boards, Xiangya School of Nursing, Central South University (Approval number: 2017035). All residents (or their proxies) and staff in the study will be provided with information packs so that they can give informed and written consent. Residents (or their proxies) and staff and nursing homes will be given a unique numerical code to ensure anonymity. Information provided by residents (proxies) and staff will be collected in a de-identifiable form and treated confidentially. Data collected in this study will be stored in a secure area in the University in which the first author is employed. All data related to the study will be accessible only to the researchers. 


\section{Competing interests}

The authors declare that they have no competing interests.

\section{Publisher's Note}

Springer Nature remains neutral with regard to jurisdictional claims in published maps and institutional affiliations.

\section{Author details}

'Xiangya school of nursing, Central South University, Changsha, Hunan province, China. ${ }^{2}$ College of Nursing and Health Sciences, Flinders University, GPO Box 2100, Adelaide, SA 5001, Australia. ${ }^{3}$ South Australian Health and Medical Research Institute, Adelaide, South Australia, Australia. ${ }^{4}$ Henan Provincial Peoples Hospital, Zhengzhou, Henan Province, China.

Received: 13 July 2018 Accepted: 2 October 2018

\section{Published online: 25 October 2018}

\section{References}

1. World Health Organization: China country assessment report on ageing and health. 2015. http://www.who.int/. Accessed 19 Oct 2018.

2. National Bureau of Statistics of People's Republic of China: Statistical Communique on National Economic and Social Development of People's Republic of China. 2016. http://www.stats.gov.cn/english/pressrelease/ 201702/t20170228_1467503.html. Accessed 28 Feb 2017.

3. Wang $X-Q$, Chen P-J. Population ageing challenges health care in China. Lancet. 2014;383(9920):870

4. Central People's Government of the People's Republic of China: Social Services Development Bulletin of China. 2016. http://www.gov.cn/xinwen/ 2016-07/12/content_5090289.htm. Accessed 3 Aug 2017.

5. Moyle W, Jones C, Murfield J, Thalib L, Beattie E, Shum D, et al. Using a therapeutic companion robot for dementia symptoms in long-term care: reflections from a cluster-RCT. Aging Ment Health. 2017;22:1-8.

6. Liu C, Feng Z, Mor V. Case-mix and quality indicators in Chinese elder care homes: are there differences between government-owned and privatesector facilities? J Am Geriatr Soc. 2014;62(2):371-7.

7. Australian Government Department of Health and Ageing: The PMG Kit for Aged care: An implementation kit to accompany The Australian Pain Society's Pain in Residential Aged Care Facilities: Management Strategies. 2007. https:// www.apsoc.org.au/PDF/Publications/PMGKit_2007.pdf. Accessed 18 Oct 2018.

8. Chen L. Decisions for institutionalization among nursing home residents and their children in Shanghai. Qual Health Res. 2015;25(4):458-69.

9. Morey W, Xiao L, Pavelic S, Habel L, Verbeeck J, Adams V. Clinical mentoring: final report: from evidence base to outcomes for older people. Unley: South Australia Resthaven Incorporated; 2015.

10. Chan TC, Luk JK, Chu LW, Chan FH. Low education level of nursing home staff in Chinese nursing homes. J Am Med Dir Assoc. 2013;14(11):849-50.

11. From I, Wilde-Larsson B, Nordström G, Johansson I. Formal caregivers' perceptions of quality of care for older people: associating factors. BMC Res Notes. 2015:8(1):1-9.

12. Zuniga F, Ausserhofer D, Hamers JP, Engberg S, Simon M, Schwendimann R. Are staffing, work environment, work stressors, and rationing of care related to care Workers' perception of quality of care? A cross-sectional study. J Am Med Dir Assoc. 2015;16(10):860-6.

13. World Health Organization: World report on ageing and health. 2016. http:// apps.who.int/iris/bitstream/handle/10665/186463/9789240694811_eng.pdf; jsessionid=618079DF7FD3062D1D249639B1A13173? sequence=1. Accessed 18 Oct 2018.

14. Rantz MJ, Zwygart-Stauffacher M, Hicks L, Mehr D, Flesner M, Petroski $\mathrm{GF}$, et al. Randomized multilevel intervention to improve outcomes of residents in nursing homes in need of improvement. J Am Med Dir Assoc. 2012;13(1):60.

15. Scottcawiezell J. Are nursing homes ready to create sustainable improvement? J Nurs Care Qual. 2005;20(3):203.

16. Konetzka RT, Brauner DJ, Coca Perraillon M, Werner RM. The role of severe dementia in nursing home report cards. Med Care Res Rev. 2015;72(5):562-79.

17. Xu W, Chen DW, Jin YB, Dong ZJ, Zhang WJ, Chen JW, et al, Incidence and related clinical factors of falls among older Chinese veterans in military communities: a prospective study. J Phys Ther Sci. 2015;27(2):331-9.
18. Kwong EW, Hung MS, Woo K. Improvement of pressure ulcer prevention care in private for-profit residential care homes: an action research study. BMC Geriatr. 2016;16(1):192.

19. Xu D, Kane RL. Effect of urinary incontinence on older nursing home residents' self-reported quality of life. J Urol. 2014;191(5):1342-4.

20. Moyle W, Venturato L, Cooke M, Hughes J, van Wyk S, Marshall J. Promoting value in dementia care: staff, resident and family experience of the capabilities model of dementia care. Aging Ment Health. 2013; 17(5):587-94.

21. Australian Government Department of Health: Encouraging Better Practice in Aged Care (EBPAC). 2015. https://agedcare.health.gov.au/ ensuring-quality/encouraging-better-practice-in-aged-care-ebpac. Accessed 31 Mar 2017.

22. Xiao L, Morey W. A partnership approach to evaluating evidence-based practice project in aged care. Aust Nurs Midwifery J. 2015;22(7):37.

23. National Aging Working Committee Office: Statistical Bulletin on Aging Development of Hunan Province. 2015. http://www.cncaprc.gov.cn/. Accessed 12 Oct 2016

24. Jeon YH, Simpson JM, Li Z, Cunich MM, Thomas TH, Chenoweth $L$, et al. Cluster randomized controlled trial of an aged care specific leadership and management program to improve work environment, staff turnover, and care quality. J Am Med Dir Assoc. 2015;16(7):629.e19-28.

25. Cox H, Puffer S, Morton V, Cooper C, Hodson J, Masud T, et al. Educating nursing home staff on fracture prevention: a cluster randomised trial. Age Ageing. 2008;37(2):167.

26. Andre B, Sjovold E, Rannestad T, Ringdal GI. The impact of work culture on quality of care in nursing homes--a review study. Scand J Caring Sci. 2014; 28(3):449-57.

27. Scott J, Vojir C, Jones K, Moore L. Assessing nursing homes' capacity to create and sustain improvement. J Nurs Care Qual. 2004;20(1):36-42.

28. Zhong XB, Lou WW. Person-centered care in Chinese residential care facilities: a preliminary measure. Aging Ment Health. 2013;17(8):952-8.

29. Jacobsen FF, Mekki TE, Førland O, Folkestad B, Kirkevold Ø, Skår R, et al. A mixed method study of an education intervention to reduce use of restraint and implement person-centered dementia care in nursing homes. BMC Nurs. 2017;16(1):55.

30. Fu J, Sun W, Wang Y, Yang X, Wang L. Improving job satisfaction of Chinese doctors: the positive effects of perceived organizational support and psychological capital. Public Health. 2013;127(10):946-51.

31. Zhang L, Huang L, Liu M, Yan H, Li X. Nurse-physician collaboration impacts job satisfaction and turnover among nurses: a hospital-based cross-sectional study in Beijing. Int J Nurs Pract. 2016;22(3):284-90.

32. Shou J, Ren L, Wang H, Yan F, Cao X, Wang H, et al. Reliability and validity of 12-item short-form health survey (SF-12) for the health status of Chinese community elderly population in Xujiahui district of Shanghai. Aging Clin Exp Res. 2016;28(2):339-46.

33. Roen I, Selbaek G, Kirkevold O, Engedal K, Lerdal A, Bergh S. The reliability and validity of the Norwegian version of the quality of life in late-stage dementia scale. Dement Geriatr Cogn Disord. 2015;40:233-42.

34. Campbell MK, Elbourne DR, Altman DG. Group C. CONSORT statement: extension to cluster randomised trials. BMJ. 2004;328:702-8.

35. Bland JM, Altman DG. Comparisons against baseline within randomised groups are often used and can be highly misleading. Trials. 2011;12:264.

36. Kim SC, Ecoff L, Brown CE, Gallo AM, Stichler JF, Davidson JE. Benefits of a regional evidence-based practice fellowship program: a test of the ARCC model. Worldv Evid-Based Nu. 2017;14(2):90-8.

37. Travers C, Graham F, Henderson A, Beattie E. CogChamps - a model of implementing evidence-based care in hospitals: study protocol. BMC Health Serv Res. 2017;17(1):202.

38. Spalding G, Stikes R, Sparks K, Myers J, Logsdon MC. Research champions: an initiative to improve use of research evidence in nursing practice. Nurses Prof Dev. 2016;32(2):E1-5.

39. Gillham D, De Bellis A, Xiao L, Willis E, Harrington A, Morey W, et al. Using research evidence to inform staff learning needs in cross-cultural communication in aged care homes. Nurse Educ Today. 2018;63:18-23.

40. Colón-Emeric CS, Corazzini K, McConnell ES, Pan W, Toles M, Hall R, et al. Effect of promoting high-quality staff interactions on fall prevention in nursing homes: a cluster-randomized trial. JAMA Intern Med. 2017;177(11):1634-41.

41. Roos C, Silen M, Skytt B, Engstrom M. An intervention targeting fundamental values among caregivers at residential facilities: effects of a 
cluster-randomized controlled trial on residents' self-reported

empowerment, person-centered climate and life satisfaction. BMC Geriatr. 2016;16:130

42. Xiao LD, Wang J, He GP, De Bellis A, Verbeeck J, Kyriazopoulos H. Family caregiver challenges in dementia care in Australia and China: a critical perspective. BMC Geriatr. 2014;14:6.

43. National Health and Family Planning Commission of the People's Republic of China: Basic standards for the nursing homes' clinic and nursing station. 2014. http://www.gov.cn/xinwen/2018-02/02/content_ 5263036.htm. Accessed 18 Oct 2018.

Ready to submit your research? Choose BMC and benefit from:

- fast, convenient online submission

- thorough peer review by experienced researchers in your field

- rapid publication on acceptance

- support for research data, including large and complex data types

- gold Open Access which fosters wider collaboration and increased citations

- maximum visibility for your research: over $100 \mathrm{M}$ website views per year

At BMC, research is always in progress.

Learn more biomedcentral.com/submissions 